\title{
ANALYSIS OF POLYNOMIAL FUNCTIONS FOR DETERMINING MAXIMUM OR MINIMUM CONDITIONS IN BIOLOGICAL SYSTEMS
}

\author{
Eugene H. Studier, Richard W. Dapson and Roger E. Bigelow \\ Department of Biology, University of Michigan, Flint, Flint, MI 48503, U.S.A.
}

(Received 31 July 1974)

\begin{abstract}
When physiological condition is curvilinearly related to environmental conditions, the "optimum" environmental condition is frequently determined by intersecting two straight lines.

2. Errors in this method are discussed, and a more precise method is suggested.

3. The curvilinear function is described by polynomial regression.

4. Optimum values of the independent variable (i.e. those resulting in maximum or minimum physiological responses) are found where the slope is zero, and can be calculated easily from the first derivative of the regression line.

5. Two examples are given: heart rate-temperature and oxygen consumption-pH.
\end{abstract}

MANY curvilinear functions are studied in a wide variety of biological systems. Examples include enzyme reaction rates as affected by temperature or $\mathrm{pH}$, metabolic rates or heart rates as affected by temperature, etc. It is often desirable to determine maximum states for the dependent variable, such conditions often characterizing physiological optima: e.g. pH optima, temperature optima, thermal neutral point. Frequently, the optimal level of the independent variable is estimated from the intersection of two straight lines (Fig. 1). These lines are derived by least squares regression analysis on data above and below the optimal level. However, the shape of the curvilinear function affects the accuracy of the estimate. Error in the estimate of $Y$ is proportional to the difference between the slopes of the two straight lines, and produces overestimates

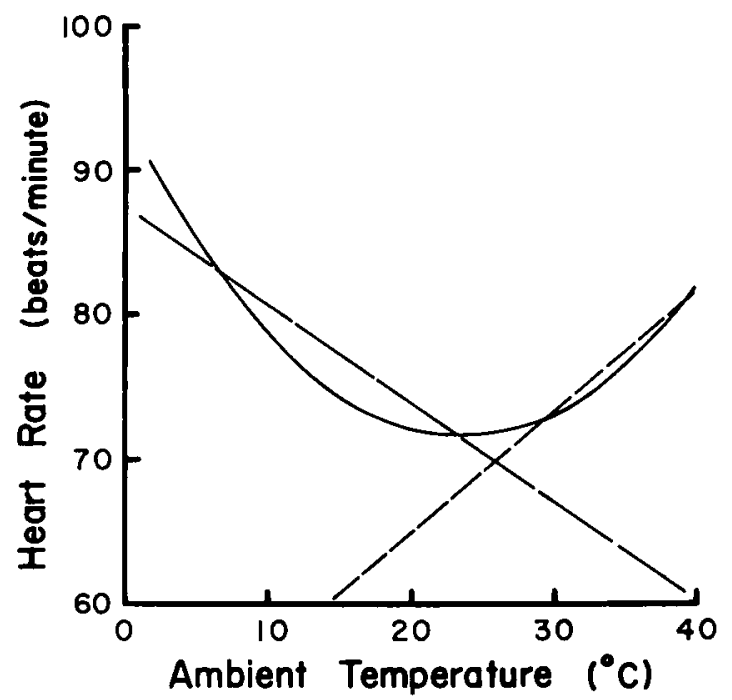

Fig. 1. Linear and polynomial regression lines describing heart beat rate of humans at different temperatures. Dashed lines illustrate how optimum temperature is estimated with intersecting straight lines. Solid curve represents polynomial regression line. for maxima and underestimates for minima. Furthermore, the error in estimating $X$ is proportional to the degree of skewness and inversely related to the direction of skewness.

At the risk of sounding trivial, we propose a more precise method, which is seldom used despite its elementary nature. Ideally, one would like an estimate of the variables at the point where the slope of the curve is zero. This requires one equation for the entire curve, and some means of locating points where the slope is zero. The ready availability of computers now allows for practical calculation of least squares polynomial regression lines of the form

$$
\hat{Y}_{i}=a+\sum_{j=1}^{m} b_{j} X_{i}^{j}
$$

where $j$ is any exponent from 1 to $m$ (Zar, 1974: 269). Procedures for fitting polynomial curves to data are available from several standard biostatistics texts (Steel \& Torrie, 1960; Sokol \& Rohlf, 1969; and Zar, 1974); confidence limits are discussed by Bliss (1970). The first derivative of a polynomial regression line is set equal to zero, using the equation:

$$
\mathrm{d} Y / \mathrm{d} X=0=\sum_{j=1}^{m}\left(b_{j}\right)(j)\left(X_{i}^{j-1}\right)
$$

Solved for $X$, the roots of this equation are the values at which the slope is zero. However, not all will be optima, and visual inspection of the graph is needed to identify important values.

As an example (Fig. 1), we recently collected data on heart beat rate $(R$ in beats/min) of 18 college-aged men and women at $5,15,25,35$ and $40^{\circ} \mathrm{C}$ ambient temperatures $(T)$. The second order regression line which best describes the relationship of heart beat rate to ambient temperature is:

$$
R=93.76-1.89 T+0.04 T^{2}
$$

The first derivative of this equation is:

$$
\mathrm{d} R / \mathrm{d} T=-1.89+0.08 T
$$




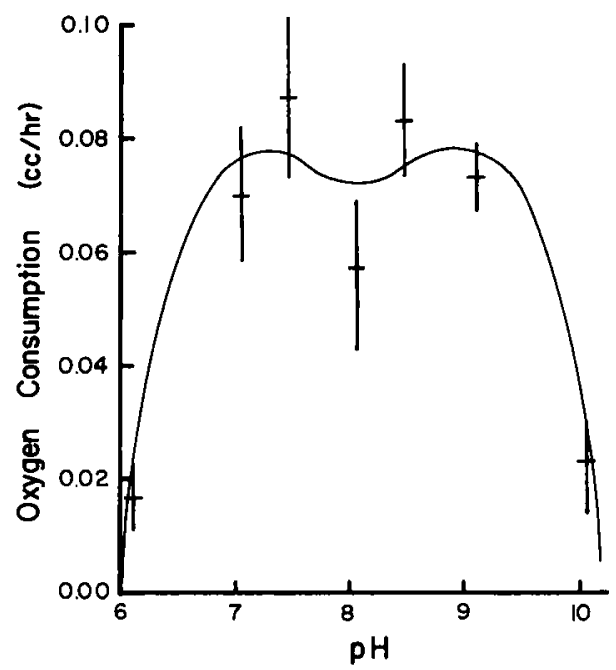

Fig. 2. Oxygen consumption in snails as a function of $\mathrm{pH}$. For each $\mathrm{pH}$ value studied, mean oxygen comsumption \pm 2 standard errors are shown.

When $\mathrm{d} R / \mathrm{d} T$ equals zero, $T=23 \cdot 6^{\circ} \mathrm{C}$. The corresponding value of heart beat rate, derived from the regression equation, is 71.5 beats/min. Solving two straight line equations generated from the data at 5,15 and $25^{\circ}$ and at 25,35 and $40^{\circ} \mathrm{C}$ yields an optimal $T$ value of $25.8^{\circ} \mathrm{C}$ at an estimated minimum of 69.9 beats/ min.

A more complex case using higher order polynomials is shown in Fig. 2. Metabolic rate $\left(\mathrm{cm}^{3} \mathrm{O}_{2} / \mathrm{hr}\right)$ of snails (Viviparus contectoides) was measured at various $\mathrm{pH}$ values ranging from $6 \cdot 1$ to $10 \cdot 1$. There are two max- ima apparent, and polynomial regression analysis is the only practical way to estimate their values. The equation is:

$$
\begin{aligned}
Y=-23.5689+11.7874 X- & 2 \cdot 1942 X^{2} \\
& +0.1808 X^{3}-0.0056 X^{4}
\end{aligned}
$$

and its first derivative is:

$\mathrm{d} Y / \mathrm{d} X=11 \cdot 7874-4.3885 X+0.5423 X^{2}-0.0222 X^{3}$

Solving for $X$ when $\mathrm{d} Y / \mathrm{d} X=0$ produces three real roots corresponding to the $\mathrm{pH}$ values at which the slope is zero: $7 \cdot 2,8 \cdot 2$ and $9 \cdot 0$. The first and last values represent maxima. The polynomial equation can now be solved with these $X$ values to give corresponding metabolic rates: 0.076 and $0.075 \mathrm{cc} / \mathrm{hr}$ at $\mathrm{pH} 7.2$ and $9 \cdot 0$ respectively.

Acknowledgement-We thank Dr. Jerrold H. Zar for his comments on an earlier draft of this paper.

\section{REFERENCES}

Buiss C. I. (1970) Statistics in Biology, Vol. II, p 639. McGraw-Hill, New York.

SoKol R. R. \& RoHLF F. J. (1969) Biometry. W. H. Freeman, San Francisco. p 776.

Steel R. G. D. \& Torrie J. H. (1960) Principles and procedures of statistics. McGraw-Hill, New York. p 481.

Zar J. H. (1974) Biostatistical Analysis. Prentice-Hall, Englewood Cliffs, N.J. p 620.

Key Word Index-Polynomial functions; optimum conditions; heart rate; oxygen consumption. 